\title{
Special Article: Physician Burnout-The Experience of Three Physicians
}

\author{
Robert A. Raschke, MD \\ University Banner Good Samaritan Medical Center \\ Phoenix, AZ
}

Our fellowship held a discussion on physician burnout which was facilitated by Kris Cooper $\mathrm{PhD}$, a psychologist who has long experience working with struggling physicians. We were joined by three physicians who volunteered to share their personal experiences regarding burnout. Each of these three physicians are exceptional in their devotion to their profession, high self-expectation, and level of professional achievement. Yet the commendable personal characteristics they share may have actually set them up to ultimately suffer burnout. Each of them responded to burnout in a different way.

The first physician is an intensivist who left work suddenly 6 months ago, likely never to return. Over a long career, this physician had earned the respect of his colleagues and was beloved by the nurses for seeming to always knowing the right thing to do and dedicating himself fully to the care of the sickest patients and their families. For most of his career he rarely experienced anxiety even under the most stressful situations - "I did not even know really what it meant to be anxious". He typically slept soundly 8 hours a night no matter what had happened at work. But nearing the end of his career he felt he had been floundering, essentially "propped-up" by the housestaff and his partners as he became progressively unable to function. At the time of his sudden departure, he was suffering unremitting insomnia, anxiety, and low self-confidence. He routinely avoided taking the sickest patients. His anxiety became so severe that he suffered anticipatory nausea even when simply accepting hand-off of the ICU service by phone.

He relates the beginning of his professional difficulties to seven years previously when his wife of 20 years unexpectedly announced her intention to divorce him. This was emotionally highly traumatic and essentially caused a situation of unremitting stress both at work and at home. He recalled often having to deal with divorce lawyers even while at work - once having been called by a lawyer while was trying to run a code. He was not able to remediate his marriage. The process was frustrating and costly, however, he was able to seemingly recover over a prolonged course. He continued functioning at a high level at work during this process and for a number of years afterwards however he found himself socially isolated and with new financial worries.

Several years later a series of complaints were lodged against him at work. In one case, he was reprimanded for publically berating a colleague regarding an inappropriate patient transfer to the ICU. Several of his patients suffered bad outcomes and were submitted for peer review. However, the reviewers were not intensivists, and he felt were not truly "peers" in the sense that they couldn't relate to the types of decisions required in ICU emergencies. In one case, a hematologist criticized his decision to give activated factor VII to a patient who was coding from uncontrollable obstetrical 
hemorrhage after the blood bank was unable to provide plasma. It was decided that his action in this case was outside the standard of care, although the reviewer did not offer any therapeutic alternative. In another incident, the physician extubated a patient who was subsequently unable to maintain independent breathing. Attempts to reintubate were unsuccessful and consequently fatal. In each case, the physician knew he had done the best he possibly could for the patient, but this chain of events cumulatively resulted in enduring workplace anxiety and a loss of self-confidence. Although he continued to provide good patient care, he felt he was "faking it", by avoiding the sickest patients and leaning heavily on residents and fellows. He sometimes asked as many as three physicians (a critical care colleague, surgeon, and anesthesiologist) to back him up when one of his patients required endotracheal intubation, although his airway skill level demonstrated over the long course of his career was excellent.

A tremor which he had suffered with for several years worsened, making it even more difficult to perform procedures. He complained of neck pain and arm weakness but a neurological evaluation was unrevealing. He was repeatedly sick with the stomach flu and upper respiratory tract infections. He was diagnosed with depression, anxiety and post-traumatic stress disorder (PTSD), but prescription medications provided no benefit and seemed to worsen somatic complaints. Insomnia became unremitting. He would go for weeks on end, sleeping only a few hours per night, or not at all. Although he was overcome by anxiety, he became detached from more situationally-appropriate emotions - relating that he could run a code, watch the patient die, then "go right to the doctor's lounge and eat a cheeseburger"- as though his feelings about things that were happening around him were irrelevant. The realization that he could no longer go on this way hit him suddenly and somewhat expectedly, although in retrospect it should have been obvious much sooner.

Up to 50\% of physicians and nurses experience "burnout" at some point in their career the highest incidence is in critical care (1). Burnout is characterized by the triad of emotional exhaustion, depersonalization, and a loss of any satisfaction in doing your job. It is caused by long term exposure to emotionally demanding situations in an environment of high responsibility and low control. Physicians with high empathy and high self-expectation and introspection are particularly at risk. It is associated with having made mistakes, perceptions of unreasonable work demands, feeling unsupported by the organization, and interpersonal conflicts. Symptoms include somatic complaints, frequent minor illnesses, social withdrawal, cynicism, exhaustion, and feeling underappreciated and overworked. Burnout may overlap with compassion fatigue, PTSD, depression, anxiety, alcoholism and drug abuse in some providers. The risk of suicide is increased by $600 \%$ for physicians, particularly female physicians.

The first physician said that he had a number of strikes against him, and took a number of wrong turns along the way. He recalled coming home from work exhausted many nights, and having no one to talk to, but at the same time, turning down opportunities to socialize more with friends. He felt he sometimes created more workplace stress than necessary by futilely resisting the hospital administration on a number of trivial issues. His partners were supportive, but really did not understand enough about what he was 
going through to effectively help him. He waited too long to get himself out of the environment.

But since removing himself from the ICU, he has been slowly improving under professional guidance. At this point, he has been away from work for about six months. [Many of the ICU staff - nurses and physicians alike - consider him the finest doctor they have ever worked with, and often ask when he can return.] But he is fairly certain that he will ever be able to return to work in the ICU.

The second physician is a highly respected intensivist who retired about a year ago, unrelated to burnout. He was described by the first physician as "the best intensivist that I ever met over the course of my career". However, the second physician suffered significant setbacks and frustration that greatly reduced enjoyment of his career. He distinguished himself as being "fed-up" vs. being burned-out by saying that if we asked him to come into the ICU tomorrow to cover a shift, he would be eager to chip-in. $\mathrm{He}$ also distinguished himself from the first physician by acknowledging that his wife of 42 years had been a huge source of support throughout the course of his many professional setbacks.

In the 1980s, in an era long before the practice of palliative care was accepted, he recalled being approached by several families of patients with end-stage COPD. At the time such patients often suffered through prolonged courses of futile ventilatory support before dying. He made a personal decision to instead offer these patients the option of morphine palliation. This was of clear benefit to his patients, but was considered well outside the standard of care at the time. He was accused of performing euthanasia, and his medical license was threatened. He was offered a deal to continue practicing medicine if he would desist and admit that what he had been doing was wrong. But his wife reassured him that he was doing the right thing and advised him not to give in. He successfully fought the complaint and continued practice. He earned a reputation for being one of the hardest-working, dedicated, and experienced physicians in the city.

In the 1990s, at the peak of his career, he diagnosed a patient with Miller Fisher variant of Guillain Barré, and placed a subclavian line to accomplish therapeutic plasmapheresis. He had previously placed perhaps thousands of subclavian lines over the course of his career. This time however, he lacerated the subclavian artery during the procedure. The patient suffered a life-threatening hemothorax requiring emergent surgical repair. The patient slowly recovered over a month-long ICU stay, during which the physician rarely left the hospital. But despite the eventual favorable outcome, he was sued, and a settlement was not reached. The case went to trial. He recalls that his wife sat in court with him every day. Ultimately he was exonerated by the jury, and he feels his wife's constancy at his side was likely favorable in their eyes. But the cumulative stress of the traumatic and prolonged legal process changed how he felt about coming to work in the ICU. He tried to return, but his partner convinced him that he needed a break from patient care. He became a successful researcher for a few years. Then he tried his hand at general internal medicine "which was terrible - unless you enjoy writing Percocet scripts for everyone". He even did a stint as an administrator, 
which he felt was a mistake in retrospect "you can't make yourself into something you are not". Eventually, he found his way back to critical care, which he still says is "in my DNA". Although now retired, he enthusiastically volunteers to do locums work in the ICU (but only with his wife's approval) and remains a highly effective bedside intensivist and great favorite of the entire ICU staff.

This physician felt several things helped explain his ability to survive the difficult tribulations of his career. He credits his wife being by his side, and his work partner for actively intervening when he was floundering but did not see that he needed a break from patient care. He also thinks his personal philosophy helped him deal with setbacks. "Essentially, bad things happen in the ICU. If you gave it all that you could, you ought to be able to live with yourself, no matter how things turn out. If you cannot do that, you won't last long in the ICU".

The third physician pioneered his specialty in the state of Arizona. When he went into single practice in the 1980s, he estimates that he went at least three years without having a single night that wasn't interrupted by a pages or phone calls. On top of his rapidly growing patient practice, he travelled around the state, lecturing at dozens of venues to establish his specialty in the state. As his practice grew, physicians started to refer him their most complicated patients, many of whom already had complicated medical-legal issues before he was involved. This resulted in his being included in multiple law suits. At one point he was named in over two dozen open suits. Even though he was not found guilty of malpractice in a single case, the cumulative stress of repeated medical legal conflicts took a heavy toll on him. He felt that there was absolutely no support available from the hospitals he worked at, or from professional societies of that time period. He became irritable, angry, and increasingly disengaged. "If you want to know if you're burned-out, just ask your wife". He began suffering a series of physical complaints including headaches, palpitations, blepharospasm, and symptoms of irritable bowel for which extensive medical workups were negative. Finally one day he snapped. His pager went off for the ten-thousandth time, and he put his fist through the wall, and told his wife "that's it - I'm though with (expletive deleted) medicine".

Fortunately his partners supported his decision to step back from patient care, but advised him to concentrate his considerable experience and interpersonal and organizational skills into the administrative side of their practice. He subsequently achieved a high level of accomplishment and job satisfaction, and currently runs the national professional society of his specialty.

This physician subsequently became a strong advocate for recognition of physician burnout, within his practice, and within his specialty on a national level. He offered some good advice for the audience: Learn what burnout is. If you have the symptoms, you have to stop pretending you're not burned-out and get professional help. If you notice behaviors of burnout in a colleague, reach out and talk to them.

He pointed out a number of ways to resist the effects of burnout: 
- Maintain harmony in your life. It's not all about work. Family, community, your personal needs, and your spirituality should all be integrated into a healthy lifestyle.

- Do something non-medical that you love to do every day - whether that is walking your dog, playing guitar or reading a good (non-medical) book.

- Get some control of your work schedule and how many hours you are working. Overwork will ultimately ruin both your productivity and the quality of your care. Remember why you went into medicine.

- Don't build a lifestyle that fosters greed. Studies have shown that once a relatively modest income is achieved, more money does not make life more satisfying or happy. Be altruistic.

- The best way to feel good about yourself is by helping others.

- Meditate each day about the good things that happened and people that you helped, rather than allow your mind to ruminate on negative events and worries.

- If you have interpersonal stress, talk to the person who is the source. Except for the occasional adversary with a personality disorder, open communication usually relieves interpersonal tensions.

- Exercise regularly - Your brain and body are connected.

- Don't accept a job in which you are routinely asked to sacrifice important life experiences, such as being with your children as they grow up. These experiences cannot later be replaced by or compensated for by job promotions or greater financial income.

\section{Reference}

1. Embriaco N, Papazian L, Kentish-Barnes N, Pochard F, Azoulay E. Burnout syndrome among critical care healthcare workers. Curr Opin Crit Care. 2007;13(5):482-8. [CrossRef] [PubMed] 